\title{
REPOSITÓRIO DIGITAL: A DELIMITAÇÃO DE UM CONCEITO POR MEIO DE MAPA CONCEITUAL
}

\author{
DIGITAL REPOSITORY: DELIMITING A CONCEPT \\ THROUGH A CONCEPT MAP
}

Denise Oliveira de Araújoa
Márcio Bezerra da Silvab

\begin{abstract}
RESUMO
Objetivo: Conceitua repositório digital a partir de um conjunto de características apresentadas como essenciais pela literatura. Propõe um modelo conceitual a partir dos predicados identificados. Adota os mapas conceituais como um caminho para organizar e representar o conhecimento sobre repositório digital, encarado como objeto de estudo na pesquisa. Metodologia: Realiza um levantamento bibliográfico que seguiu quatro passos, ou seja, identificação de características, definição de categorias para agrupar os atributos identificados, desenho do protótipo (em papel), estruturação do prototipado em software livre específico e apresentação do mapa conceitual. Inspira-se nos estudos de Joseph Novak (Teoria da Aprendizagem Significativa), originando um mapa conceitual do modelo aranha, desenhado e apresentado de maneira descritiva e qualitativa. Resultados: Resulta em um mapa conceitual construído no software CmapTools, estruturado por características essenciais dos repositórios digitais, sendo elas: interatividade e colaboração; interoperabilidade; acessibilidade; gerenciamento; autoarquivamento; pacote de software; e preservação. Conclusões: Constitui um sistema uno e conciso, baseado em padrões abertos, interoperáveis e alinhados ao incentivo de implementação a partir de softwares livres e de código aberto, os quais preveem gestão, autoarquivamento e representação, assim como acesso a posteriori aos seus objetos digitais e a memória institucional a qual está subordinado.
\end{abstract}

Descritores: Organização e Representação do Conhecimento. Repositório digital. Mapa conceitual. CmapTools.

\section{INTRODUÇÃO}

A Sociedade da Informação, eclodida no fim do século XX, inaugurou um modelo técnico-econômico, cujo âmago assenta-se nas tecnologias da

\footnotetext{
a Mestranda em Ciência da Informação pela Universidade de Brasília (UnB). E-mail: deoliveiraraujo@gmail.com

b Doutor em Ciência da Informação pela Universidade Federal da Bahia (UFBA). Docente da Faculdade de Ciência da Informação da Universidade de Brasília (FCl-UnB). E-mail: marciobdsilva@unb.br
} 
informação e comunicação (TICs) e suas constantes evoluções (WHERTHEIN, 200). Desde então, surgem iniciativas centradas na otimização da conversação entre sistemas de informação (SIs), como é o caso da Open Archives Initiative (OAI), via protocolos Open Archives Initiative Protocol for Metadata Harvesting (OAI-PMH) e Open Archives Initiative Object Reuse and Exchange (OAI-ORE), assim como a ascensão do Movimento de Acesso Aberto (MAA) (início do século XXI) oriunda da Budapest Open Access Initiative (BOAI), fomentando o acesso irrestrito às publicações científicas (BAPTISTA et al., 2017).

As iniciativas supramencionadas (OAl e MAA), impactaram nos processos de Comunicação Científica (CC) ao apresentarem um conjunto de alternativas focadas em minimizar problemáticas associadas à explosão informacional, além de outras implicações decorrentes da difusão da web. Elencam-se, portanto, os Repositórios Digitais (RDs), entendidos como Sls destinados ao armazenamento e recuperação de objetos digitais (ODs) e comunicação entre usuários (SAYÃO; MARCONDES, 2009; BAPTISTA et al., 2017).

O desejo por mais especificidades que contextualize e define RD suscita dúvidas sobre meios de armazenamento, formas de descrição, alternativas para interatividade e colaboração, pacotes de software etc. A Organização e Representação do Conhecimento (ORC) se apresenta como um caminho para significá-los, pois trata-se, segundo Rodrigues e Cervantes (2014), de uma maneira de sistematização temática que almeja o alcance de determinado objetivo, sendo constituída, simultaneamente, pela união entre categorias (organização), as quais representam o objeto de conhecimento, e ação (representação), que engloba, dentre outras coisas, a geração de instrumentos, com a finalidade de aplicação no âmbito Institucional.

Entre os modelos de ORC destacam-se os mapas conceituais (MCs), entendidos como "[...] diagramas hierárquicos que mostram a organização e correspondência entre conceitos, que são apresentados por uma diferenciação progressiva [...] ou por uma reconciliação integrativa [...]" (CARABETTA JÚNIOR, 2013, p. 443), modelo que justifica o interesse em conceituar o objeto $\mathrm{RD}$ a partir de características essenciais. Para tanto, propõe-se um MC a partir dos predicados angariados na literatura. 


\section{PROCEDIMENTOS METODOLÓGICOS}

Pesquisa dedutiva e qualitativa que investigou o objeto $\mathrm{RD}$, descrevendoo a partir de um levantamento bibliográfico, empreendida, originalmente, entre agosto de 2018 e julho de 2019, tendo sido feito, para fins de atualização, um novo levantamento em outubro de 2021, a partir do qual não foram identificados novos atributos além dos anteriormente arrolados no estudo.

O levantamento bibliográfico resultou-se da combinação das seguintes expressões de busca: ("digital repository" OR "digital repositories" OR "repositório digital" OR "repositórios digitais") AND (atributes OR features OR characteristics OR características). Esse levantamento foi possível pela consulta às literaturas nacional e internacional, em livros, artigos de periódicos e apresentados em eventos, teses, dissertações, projetos de lei e relatórios técnicos. No caso, o estudo percorreu cinco passos:

1) identificação das características adjacentes aos RDs na literatura;

2) definição de categorias para agrupar os atributos identificados;

3) desenho do protótipo (em papel);

4) estruturação do protótipo no software livre CmapTools (versão 6.03.01), adotando figuras geométricas específicas e incorporando links aos atributos levantados (Figura 1);

5) apresentação do $\mathrm{MC}$, contendo a organização dos predicados considerados essenciais para significar RD.

Figura 1 - Lógica geométrica utilizada

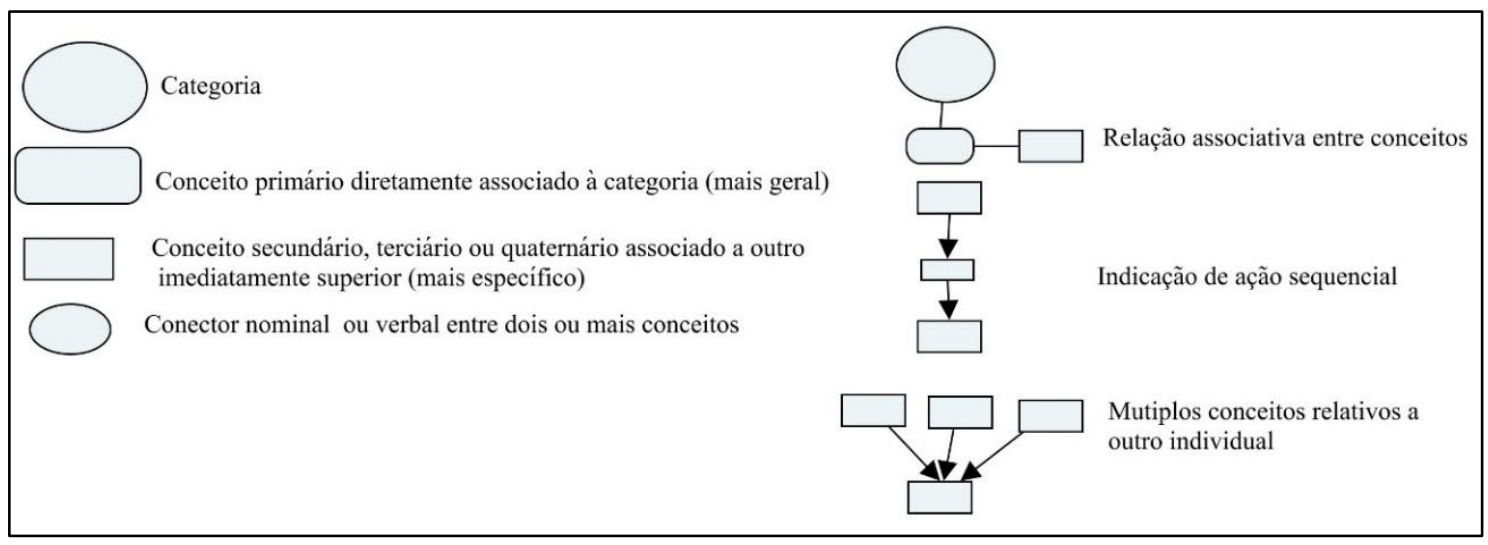

Fonte: Elaborada pelos autores (2019) 
Vencida a primeira etapa, partiu-se para a elaboração do MC, construído primeiramente em papel e posteriormente transposto para o software livre CmapTools. Ao longo da construção do $\mathrm{MC}$, intentou-se estabelecer um alinhamento com os estudos do professor Joseph Novak (Teoria Cognitivista da Aprendizagem - TCA), como um modelo premeditado ao ato de "aprender a aprender", fomentando uma aprendizagem significativa em detrimento da tradicional, apoiada nos atos de repetição mecânica e memorização (NOVAK, 1990; GONZÁLEZ GARCIA, 1992; MOREIRA, 2010).

Diante da inexistência de uma regra para elaboração de MCs (MOREIRA, 2010), optou-se pelo emprego do "mapa aranha", aliado a uma camada hierárquica à medida que um conceito central se desdobra em outros a ele associados, o que demanda um nível de subordinação. A Figura 2 ilustra um exemplo da estrutura elegida, em camadas hierárquicas.

Figura 2 - MC aranha com camadas hierárquicas

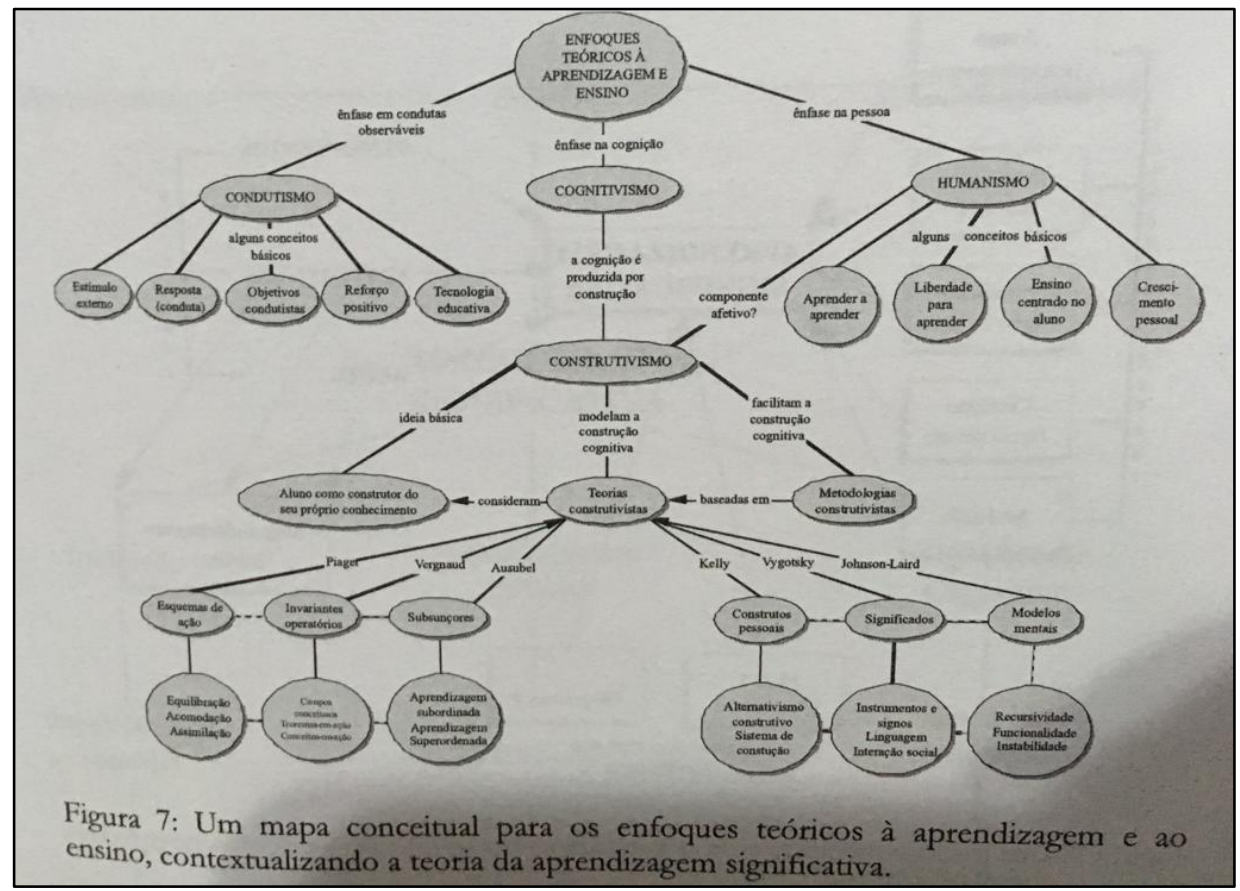

Fonte: Moreira (2010, p. 27)

À luz da Figura 2, o protótipo que compôs o terceiro passo metodológico resultou no protótipo desenhado (manualmente) em papel, devidamente ilustrado na Figura 3. É possível observar que cada categoria é diferenciada por colorações específicas, ajudando-as a serem visualmente distintas. 


\section{Figura 3 - Protótipo de MC em papel}

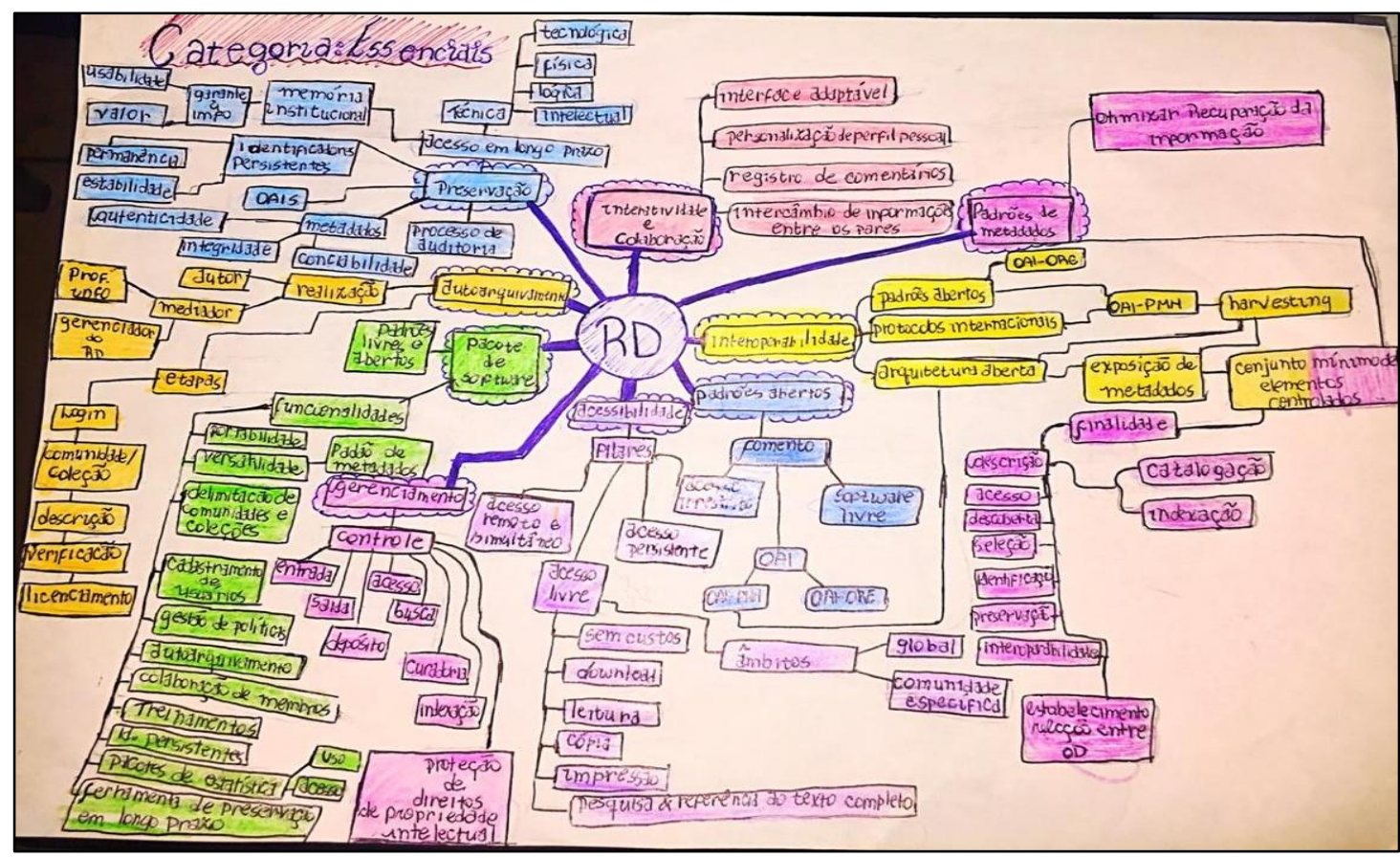

Fonte: Elaborada pelos autores (2019)

$\mathrm{Na}$ intenção de conceituar RD, os predicados (Figura 3) foram agrupados pelas seguintes categorias: interatividade e colaboração; interoperabilidade; padrões abertos; autoarquivamento; padrões de metadados; preservação; pacote de software; capacidade de gerenciamento; e acessibilidade.

\section{REPOSITÓRIOS DIGITAIS}

$\mathrm{Na}$ literatura identificou-se uma multiplicidade de elementos associados aos variados tipos de RDs, estratificados como institucionais, temáticos, de teses e dissertações e de dados. Inferiu-se que parte das características possui natureza inerente aos RDs, devido à recorrência com a qual são abordadas. Assim, no conjunto de atributos imprescindíveis, citam-se (Quadro 1):

\section{Quadro 1 - Características essenciais}

\begin{tabular}{|c|l|}
\hline Característica & \multicolumn{1}{|c|}{ Descrição } \\
\hline Interatividade e & $\begin{array}{l}\text { Interfaces adaptáveis, prevendo experimentação e dinamicidade nas } \\
\text { atividades dos usuários, como a personalização de perfil, registro de } \\
\text { colaboração } \\
\text { comentários (moderados ou não) e intercâmbio de informações entre os } \\
\text { pares (produtores ou leitores da informação), dispersos, ou não, } \\
\text { geograficamente. }\end{array}$ \\
\hline
\end{tabular}




\begin{tabular}{|c|c|}
\hline Interoperabilidade & $\begin{array}{l}\text { Processo realizado em interface única via padrões (de preferência } \\
\text { abertos) e protocolos internacionais, a fim de potencializar a } \\
\text { recuperação da informação. Recomenda-se a abertura da arquitetura do } \\
\text { sistema, possibilitando a exposição dos metadados do RD e a adoção } \\
\text { de um conjunto mínimo de campos controlados (autor, título, etc.), } \\
\text { permitindo a conversação entre Sls. É desejável participação na OAl e } \\
\text { adoção de padrões como o OAI - Object Reuse and Exchange (OAI- } \\
\text { ORE) e o OAI-PMH (indicado para harvesting, isto é, para a coleta de } \\
\text { metadados.). }\end{array}$ \\
\hline Padrões abertos & $\begin{array}{l}\text { Adotados devido à origem acadêmica dos RDs, em virtude da } \\
\text { necessidade de adquirir expertise técnica para a construção destes SIs; } \\
\text { fomento ao acesso irrestrito de acesso aos itens disponibilizados; } \\
\text { incentivo à seleção e implementação de softwares livres de código } \\
\text { aberto, prevendo a adesão de padrões desenvolvidos pela OAl, como } \\
\text { OAI-ORE e OAI-PMH, sendo este último um propulsor das arquiteturas } \\
\text { abertas que subsidiam o harvesting. }\end{array}$ \\
\hline Autoarquivamento & $\begin{array}{l}\text { Realizado pelo próprio autor ou mediador (profissional da informação ou } \\
\text { gestor do RD), promovendo celeridade na difusão da CC. Compreende } \\
\text { etapas como: login; seleção de uma comunidade ou coleção; descrição } \\
\text { do OD; carregamento do arquivo; e verificação da submissão e } \\
\text { licenciamento. Se realizado pelo próprio autor, retorna-lhe o direito sobre } \\
\text { sua produção e confere-lhe decisão sobre os meios de difusão nos quais } \\
\text { a publicação será depositada. Tem-se como entraves: falta de confiança } \\
\text { nos RDs; escasso conhecimento sobre o processo de CC; baixo } \\
\text { fomento, por parte dos órgãos competentes com a implementação de } \\
\text { medidas como o depósito compulsório. É atribuído a esta característica, } \\
\text { um nível considerado de relevância, ao passo que tende a ser vista como } \\
\text { um dos pressupostos típicos de qualquer RD, visto que este processo é } \\
\text { responsável por, de certa forma, devolver aos autores a autonomia sob } \\
\text { suas produções. }\end{array}$ \\
\hline $\begin{array}{l}\text { Padrões de } \\
\text { metadados }\end{array}$ & $\begin{array}{l}\text { Esquemas gestores e flexíveis que promovem, em um conjunto mínimo } \\
\text { de etiquetas de descrição, a descoberta, identificação, seleção, acesso, } \\
\text { preservação, interoperabilidade e estabelecimento de associações entre } \\
\text { ODs, o que agrega valor à organização da informação (OI) nos RDs, } \\
\text { devido aos rótulos (campos) controlados para indexação e catalogação } \\
\text { dos itens depositados. Ademais, contribui para a visibilidade } \\
\text { institucional. }\end{array}$ \\
\hline Preservação & $\begin{array}{l}\text { Abordada de duas formas: em termos técnicos, englobando aspectos } \\
\text { tecnológicas, físicos, lógicos e intelectuais; e em relação à salvaguarda } \\
\text { em longo prazo da memória institucional, garantido a usabilidade e o } \\
\text { valor da informação científica no futuro. As estratégias visam, ainda, a } \\
\text { criação de políticas, processos de auditoria (tornar os RDs confiáveis e } \\
\text { seguros, viabilizando o uso ao longo do tempo) e metadados } \\
\text { apropriados, visando atestar a autenticidade, integridade e } \\
\text { confiabilidade do SI e de seus itens. Refere-se, também, à atribuição de } \\
\text { identificadores persistentes destinados à identificação única, global, } \\
\text { permanente e estável de um OD. Enfim, recomenda-se o uso do modelo } \\
\text { Open Archives Information System (OAIS), que descreve informações e } \\
\text { funções para a preservação em longo prazo. }\end{array}$ \\
\hline $\begin{array}{l}\text { Pacote de } \\
\text { software }\end{array}$ & $\begin{array}{l}\text { Seleção e implementação de um pacote alinhado às especificidades } \\
\text { institucionais e, preferencialmente, baseado em padrões livres e abertos. } \\
\text { Recomenda-se que seja dotado de: portabilidade; versatilidade em } \\
\text { relação aos esquemas de metadados; delimitação de comunidades e } \\
\text { coleções; cadastramento de usuários; gestão de políticas de conteúdo, } \\
\text { autoarquivamento; colaboração pelos membros; treinamentos; geração } \\
\text { de identificadores persistentes, pacotes de estatística diversas; e } \\
\text { preservação em longo prazo. }\end{array}$ \\
\hline
\end{tabular}




\begin{tabular}{|l|l|}
\hline $\begin{array}{l}\text { Capacidade de } \\
\text { gerenciamento }\end{array}$ & $\begin{array}{l}\text { Posse de uma estrutura organizacional baseada em metadados } \\
\text { definidos segundo as demandas do SI, distinguindo-o de outros motores } \\
\text { de busca populares. Inclui a gestão de ações como: controle de entrada } \\
\text { e saída de dados; depósito; acesso; busca; curadoria informacional; } \\
\text { indexação; proteção dos direitos de propriedade intelectual; dentre } \\
\text { outros. }\end{array}$ \\
\hline Apoia-se em quatro pilares: acesso irrestrito; acesso persistente em \\
longo prazo; acesso livre de custos, compreendendo atividades de \\
download, leitura, cópia, impressão, pesquisa e referência ao texto \\
completo (a não ser que haja entraves de caráter legal); e acesso remoto \\
e simultâneo por vários usuários. O acesso gratuito, irrestrito e livre de \\
barreiras (físicas ou de outra natureza) fomenta vias alternativas à CC, \\
como a preconizada pela Green Road (incentivo ao autoarquivamento, \\
pelos próprios autores ou pela instituição), bem como a maximização da \\
visibilidade dos itens, estimulando a criação e atualização de novas \\
versões. Um RD (visto como bem público) transparente, em termos de \\
acessibilidade, não subentende a desconsideração da proteção legal \\
dos itens depositados, pois, os gestores destes Sls devem prever \\
estratégias para assegurar direitos autorais. Apesar de geralmente \\
associados a iniciativas abertas, o acesso a RDs pode ser livre em \\
âmbito global ou restrito a uma determinada comunidade que busca \\
atender.
\end{tabular}

Fonte: Association of Research Libraries (2009); Barros; Ferrer; Maia (2018); Bărbieru; Radu; Beligan (2015); Brasil (2007); Brown (2010); Camargo; Vidotti (2009); Costa; Leite, 2009; Cervone (2008); Coelho (2005); Ferreira (2008); França; Araújo; Silva (2020); Graaf; Eijndhoven (2008); Heery; Anderson (2005); Kiryakova; Yordanova (2013); Kuramoto, 2009; Lawson; Spies (2004); Leite, 2009; Márdero Arellano (2004); Monteiro (2013); Moreno; Leite; Márdero Arellano (2006); Pietro (2009); Pires (2015); Repanovici (2012); Research Libraries Group (2002); Rodrigues et al., (2011); Santarem Segundo (2010); Sayão; Marcondes (2009); Schäfer; Constante (2012); Silva; Rodrigues (2013); Souza (2015); Swan (2008); Weenink; Waaijers; Van Godtsenhoven (2008).

No agrupamento de características mais recorrentes nas fontes consultadas que versam sobre RDs, destacam-se três pontos: o primeiro deles é a consonância que a maioria desses predicados possuem com os preceitos do MAA e da Ciência Aberta, assentados no próprio acesso aberto, na reprodutibilidade da pesquisa científica e nos dados abertos, que devem ser passíveis de reuso; em segundo lugar, chama-se atenção para as estratégias de preservação digital, que apesar de não explicitadas de maneira pragmática, figuram como o atributo mais abordado pelos autores consultados; finalmente, cita-se a tônica das colocações dos autores no que tange ao autoarquivamento, que é, no geral, apresentado como um dos traços identitários dos RDs.

Após tecer o panorama de características identificadas, agrupadas em categorias específicas, na próxima seção, esse conglomerado de atributos é estruturado visualmente por meio de um MC do tipo "aranha". 


\section{RESULTADO: PROPOSTA CONCEITUAL}

As características essenciais levantadas foram, a partir do software CmapTools, representadas por figuras geométricas e cores (Figura 3). Três critérios de apresentação foram estabelecidos, diante de semelhanças conceituais e/ou técnicas subjacentes aos atributos: adoção de diferentes cores para cada agrupamento; utilização de uma única cor para cada agrupamento, de modo a identificar o atributo e os respectivos predicados a ele associados; e compartilhamento de tonalidades entre características recorrentes em mais de um agrupamento. A exibição visual dos critérios adotados é exemplificada por um trecho do MC, ilustrado na Figura 4.

\section{Figura 4 - Exemplo de conceito}

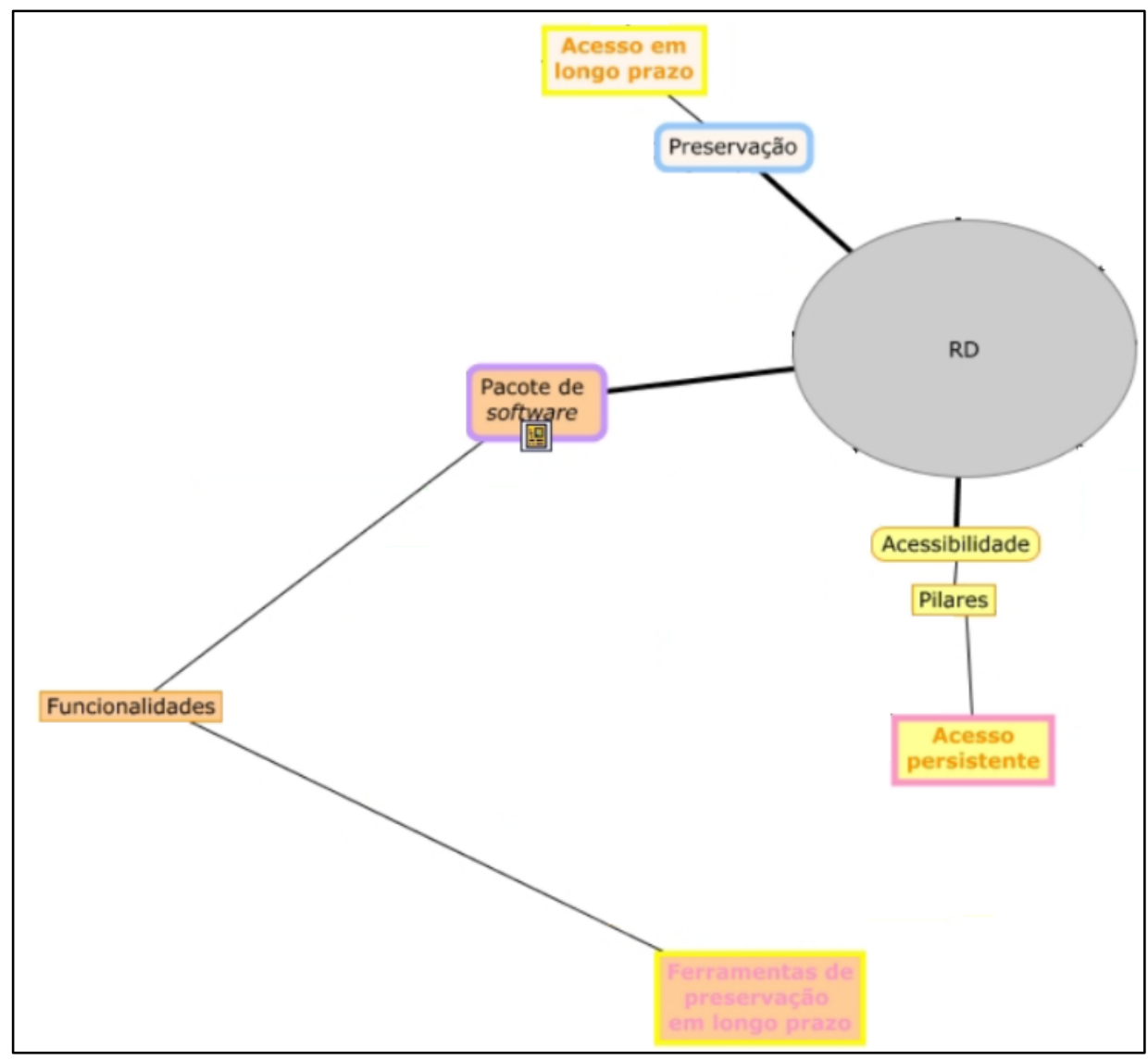

Fonte: Elaborada pelos autores (2021)

No exemplo, o atributo "acesso em longo prazo" é recorrente em três agrupamentos de características, o qual apresenta uma alternação de cores ao longo do mapa. Primeiro, quando ligado à "preservação", o atributo possui uma 
borda amarela que corresponde à cor de preenchimento de "acesso persistente", associado à categoria "acessibilidade", pois o predicado "preservação" representa um pilar da "acessibilidade" de ODs. Portanto, observa-se que a cor de preenchimento da categoria "acessibilidade" é amarela. Segundo, sobre a cor de preenchimento do atributo "acesso em longo prazo", ela é herdada da categoria "preservação", a qual está inserida. Terceiro, para as letras alaranjadas de "aceso em longo prazo", ela é advinda do atributo "ferramentas de preservação em longo prazo", subordinado a categoria "pacote de software", pois faz-se necessário adotar um programa que promova, entre suas "funcionalidades", a "preservação". Observa-se que a cor de preenchimento da categoria "pacote de software" é laranja. Enfim, o MC resultante da coleta de dados é exposto na figura 5 .

Figura 5 - MC sobre RD (características essenciais) ${ }^{c}$

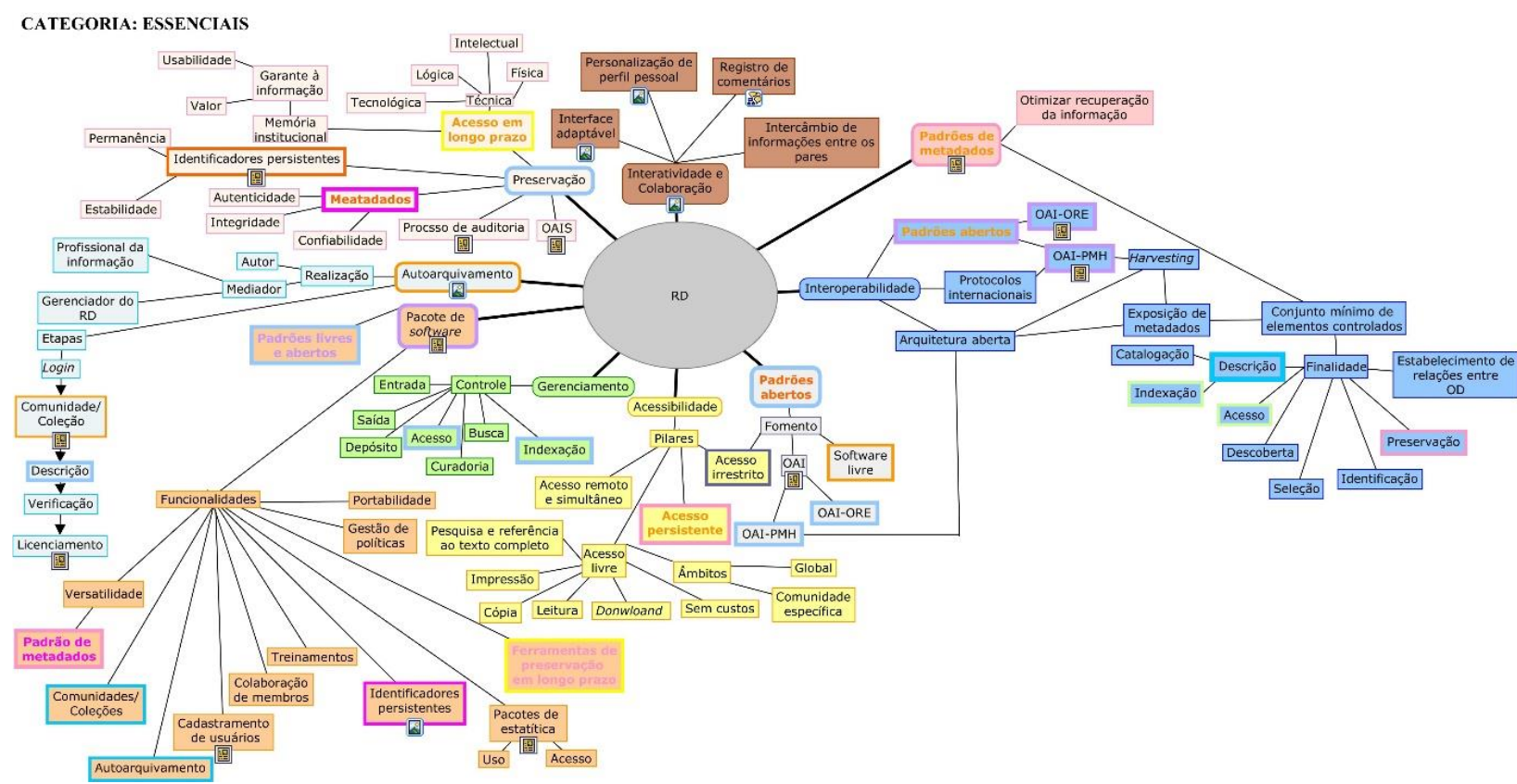

Fonte: Elaborada pelos autores, última conferência em 2020

Em termos essenciais, de acordo com a literatura angariada, infere-se que os RDs devem contar, imprescindivelmente, com a implementação de um pacote de software baseado em padrões livres e munido de funcionalidades que

\footnotetext{
${ }^{c}$ Recurso visual online: acesso. Recomenda-se a utilização do navegador Mozilla Firefox para acessar o MC interativo.
} 
subsidiem o gerenciamento do sistema. Espera-se, ainda, que esses Sls compreendam ferramentas que fomentem a interatividade e colaboração por parte da comunidade de usuários que o acessa.

Ademais, entende-se como essencial a adoção de padrões de metadados que, além de otimizarem o processo de recuperação da informação, contribuam para a consecução da interoperabilidade, a qual deve prever protocolos internacionais como o OAI-PMH. Ainda são ensejados padrões abertos e acessibilidade, fomentando o acesso livre, irrestrito, persistente e simultâneo aos ODs hospedados no repositório, e preconizando a preservação tanto da memória quanto do sistema em si. Por fim, é primordial o autoarquivamento, seja por parte do criador do item depositado, seja a partir de um mediador, visto que tal atividade constitui a essência dos RD, sendo uma tarefa que atribui autonomia aos autores sob suas produções.

\section{CONSIDERAÇÕES FINAIS}

De posse do corpus de características essenciais identificadas, a sistematização do conceito de RD deu-se pela elaboração de um MC em formato "aranha" com camadas hierárquicas, materializado no software livre CmapTools, a partir dos preceitos delimitados por Joseph Novak e à luz dos pressupostos de organização e representação que formalizam a ORC.

Categoricamente, identifica-se um agrupamento de atributos recorrentemente citados pelos pares, quando se discute o desenvolvimento de RDs, encarados como imprescindíveis: autoarquivamento; interoperabilidade; gerenciamento do sistema; adoção de pacotes de software, preferencialmente livres; fomento à interatividade e colaboração; elaboração de iniciativas de suporte à preservação digital; uso de padrões de metadados; compreensão de padrões livres; e acessibilidade irrestrita, permanente, aberta e remota. Em conformidade às informações coletadas, a adoção de estratégias eficientes de preservação digital se destaca como um dos predicados mais citados, constituindo-se como uma iniciativa de grande valia tanto para a memória institucional quanto para o acesso em longo prazo dos ODs.

Não obstante, tendo em vista a literatura consultada, não foi possível 
identificar estratégias de preservação de forma pragmática, enquanto é válido mencionar a relevância atribuída pelos autores ao autoarquivamento, bem como o alinhamento da maioria dos predicados com o ativismo em prol do acesso livre subjacente ao MMA e à Ciência Aberta.

Face ao exposto, concluiu-se que RD constitui um sistema uno e conciso, baseado em padrões abertos, interoperáveis e alinhados ao incentivo de implementação a partir de softwares livres e de código aberto, os quais preveem gestão, autoarquivamento e representação, assim como acesso a posteriori aos seus ODs e a memória institucional à qual está subordinado.

\section{REFERÊNCIAS}

ASSOCIATION OF RESEARCH LIBRARIES. The research library's role in digital repository services: final report for the ARL Digital Repository Issues Task Force. Washington, DC: ARL, 2009. Disponível em:

https://www.arl.org/storage/documents/publications/repository-services-reportjan09.pdf. Acesso em: 27 jun. 2021.

BAPTISTA, A. A.; COSTA, S. M. S.; KURAMOTO, H.; RODRIGYES, E. Comunicação científica: o papel da Open Archives Initiative no contexto do acesso livre. Encontros Bibli: Revista Eletrônica de Biblioteconomia e Ciência da Informação, Florianópolis, n. esp., p. 1-17, 2017. Disponível em: http://repositorio.unb.br/handle/10482/635. Acesso em: 29 jun. 2021.

BĂRBIERU, D.; RADU, C.; BELIGAN, D. Customization process for a multimídia digital repository. In: INTERNATIONAL SCIENTIFIC CONFERENCE ELEARNING AND SOFTWARE FOR EDUCATION, 11., 2015, Bucharest. Proceedings [...]. Bucharest: Carol I National Defence University Publishing House, 2015. p. 383-389. Disponível em:

https://proceedings.elseconference.eu/index.php?r=site/index\&year=2015\&inde $\mathrm{X}=$ papers\&vol=19\&paper $=4 \mathrm{ce} 25 f 531 \mathrm{a} 5 \mathrm{~b} 72 \mathrm{a} 5 \mathrm{~d} 3 \mathrm{cb} 7 \mathrm{c} 659 \mathrm{~b} 054719$. Acesso em: 27 jun. 2021.

BARROS, D. B. S.; FERRER, I. D.; MAIA, C. M. S. Auditoria de repositórios digitais preserváveis. Revista Ibero-Americana de Ciência da Informação, Brasília, DF, v. 11, n. 1, p. 300-313, jan./abr. 2018. Disponível em: http://periodicos.unb.br/index.php/RICl/article/view/8572. Acesso em: 27 jun. 2021.

BRASIL. Câmara dos Deputados. Projeto de Lei no 1120-B, de 2007. Brasília, DF: Câmara dos Deputados, 2007. Disponível em: https://www.camara.leg.br/proposicoesWeb/prop_mostrarintegra;jsessionid=F8 
6D3B71F1E4FCA4F9135827EBF4063D. node2?codteor $=572586 \&$ filename $=A v$ ulso+-PL+1120/2007. Acesso em: 27 jun. 2021.

BROWN, D. J. Repositories and journals: are they in conflict? A literature review of relevant literature. Aslib Proceedings: New Information

Perspective, London, v. 62, n. 2, p. 112-143, 2010.

CAMARGO, L. S. A.; VIDOTTI, S. A. B. G. Arquitetura da informação para repositórios científicos digitais. In: SAYÃO, L. F.; TOUTAIN, L. B.; ROSA, F. G.; MARCONDES, C. H. (org.). Implantação e gestão de repositórios institucionais: políticas, memória, livre acesso e preservação. Salvador: EDUFBA, 2009. p. 55-82. Disponível em:

https://repositorio.ufba.br/ri/bitstream/ufba/473/3/implantacao_repositorio_web.p df. Acesso em: 27 jun. 2021.

CARABETTA JÚNIOR, V. A utilização de mapas conceituais como recurso didático para a construção e inter-relação de conceitos. Revista Brasileira de Educação Médica, Brasília, DF, v. 37, n. 3, p. 441-447, 2013. Disponível em: http://www.scielo.br/pdf/rbem/v37n3/17.pdf. Acesso em: 27 jun. 2021.

CERVONE, F. Thinking outside the library box: considerations in contextualizing digital repositories for the local environment. OCLC Systems \& Services: International Digital Library Perspectives, [Bradford, UK], v. 24, n. 3, p. 148-152, 2008.

COELHO, C. Um repositório digital para a U.Porto: relatório preliminar. Porto: Universidade do Porto, 2005. Disponível em: https://repositorioaberto.up.pt/handle/10216/6701. Acesso em: 27 jun. 2021.

COSTA, S. M. S.; LEITE, F. C. L. Insumos conceituais e práticos para iniciativas de repositórios institucionais de acesso aberto à informação científica em bibliotecas de pesquisa. In: SAYÃO, L. F.; TOUTAIN, L. B.; ROSA, F. G.; MARCONDES, C. H. (org.). Implantação e gestão de repositórios institucionais: políticas, memória, livre acesso e preservação. Salvador: EDUFBA, 2009. p. 163-202. Disponível em: https://repositorio.ufba.br/ri/bitstream/ufba/473/3/implantacao_repositorio_web.p df. Acesso em: 27 jun. 2021.

FERREIRA, S. M. S. P. Repositórios versus revistas científicas: convergências e conveniências. In: FERREIRA, S. M. S. P.; TARGINO, M. G. (org.). Mais sobre revistas científicas: em foco a gestão. São Paulo: Editora Senac: Cengage Learning, 2008, p. 111-137.

FRANÇA, P.; ARAÚJO, D. O.; SILVA, M. B. A ferramenta para repositórios institucionais DSpace: conceitos e características. Revista Ibero-Americana de Ciência da Informação, Brasília, DF, v. 13, n. 2, p. 603-601, 2020. Disponível em: https://periodicos.unb.br/index.php/RICl/article/view/31160. Acesso em: 29 jun. 2021. 
GONZÁLEZ GARCIA, F. M. Los mapas conceptuales de J.D. Novak como instrumentos para la investigación en didática de las ciencias experimentales. Enseñanza de las Ciencias, Barcelona, v. 10, n. 2, p. 148-158, 1992.

GRAAF, M. V. D.; EIJNDHOVEN, K. V. Iventory study into the present type and level of OAI-Compliant digital repository activities in the EU.

Amsterdam: Amsterdam University Press, 2008. Disponível em: http://arno.uva.nl/document/93725. Acesso em: 27 jun. 2021.

HEERY, R.; ANDERSON, S. Digital repositories review. United Kingdom: Joint Information Systems Committee, 2005. Disponível em: http://www.ukoln.ac.uk/repositories/publications/review-200502/digitalrepositories-review-2005.pdf. Acesso em: 27 jun. 2021.

KURAMOTO, H. Repositórios institucionais: políticas e mandatos. In: SAYÃO, L. F.; TOUTAIN, L. B.; ROSA, F. G.; MARCONDES, C. H. (org.). Implantação e gestão de repositórios institucionais: políticas, memória, livre acesso e preservação. Salvador: EDUFBA, 2009. p. 203-217. Disponível em: https://repositorio.ufba.br/ri/bitstream/ufba/473/3/implantacao_repositorio_web.p df. Acesso em: 27 jun. 2021.

KIRYAKOVA, G.; YORDANOVA, L. Digital repositories: a tool for effective management of institutional assets. Trakia Journal of Sciences, Stara Zagora, BG, v. 11, p. 377-383, 2013. Supl. 1.

LAWSON, D.; SPIES, P. B. Developing a trusted digital repository: the OCLC experience. Vine, [London], v. 34, n. 1, p. 27-32, 2004.

\section{LEITE, F. C. L. Como gerenciar e ampliar a visibilidade da informação} científica brasileira: repositórios institucionais de acesso aberto. Brasília, DF: IBICT, 2009. Disponível em: http://repositorio.unb.br/handle/10482/4841. Acesso em: 27 jun. 2021.

MÁRDERO ARELLANO, M. Á. Preservação de documentos digitais. Ciência da Informação, Brasília, DF, v. 33, n. 2, p. 15-27, maio/ago. 2004. Disponível em:_http://revista.ibict.br/ciinf/article/view/1043/1113. Acesso em: 27 jun. 2021.

MONTEIRO, F. S. Web semântica e repositórios digitais educacionais na área de saúde: uma modelagem com foco no objetivo de aprendizagem para refinar resultados de busca. 2013. 202 f. Tese (Doutorado em Ciência da Informação) - Programa de Pós-Graduação em Ciência da Informação, Universidade de Brasília, Brasília, DF, 2013. Disponível em: http://repositorio.unb.br/handle/10482/13461. Acesso em: 27 jun. 2021.

MOREIRA, M. A. Mapas conceituais e aprendizagem significativa. São Paulo: Centauro, 2010.

MORENO, F. P.; LEITE, F. C. L.; MÁRDERO ARELLANO, M. Á. Acesso livre a publicações e repositórios digitais em Ciência da Informação no Brasil. 
Perspectivas em Ciência da Informação, Belo Horizonte, v. 11, n. 1, p. 82-94, jan./abr. 2006. Disponível em:

http://portaldeperiodicos.eci.ufmg.br/index.php/pci/article/view/447/258. Acesso em: 27 jun. 2021.

NOVAK, J. D. Concept mapping: a useful tool for science education. Journal of Research in Science Teaching, [S.I.], v. 27, n. 10, p. 937-949, 1990.

PIETRO, A. G. From conceptual to perceptual reality: trust in digital repositories. Library Review, [Bradford, UK], v. 58, n. 8, p. 593-606, 2009.

PIRES, D. C. G. B. Gestão da informação e do conhecimento e repositórios digitais: construindo um contexto para o surgimento das competências organizacionais. 2015. 141 f. Dissertação (Mestrado em Ciência da Informação) - Escola de Comunicação e Artes da Universidade de São Paulo, Universidade de São Paulo, São Paulo, 2015. Disponível em: http://www.teses.usp.br/teses/disponiveis/27/27151/tde-17112015-100104/ptbr.php. Acesso em: 27 jun. 2021.

REPANOVICI, A. Professional profile of digital repository manager. Library Hi Tech News, [England], v. 29, n. 10, p. 13-20, 2012.

RESEARCH LIBRARIES GROUP. Trusted Digital Repositories: attributes and responsibilities. Mountain View, CA: Research Libraries Group, 2002. Disponível em:

https://www.oclc.org/content/dam/research/activities/trustedrep/repositories.pdf. Acesso em: 27 jun. 2021.

RODRIGUES, A. P.; TAROUCO, L. M. R.; SCHIMTT, M. A. R.; CAZELLA, S. C. A interoperação com repositórios digitais: protocolos e exemplos. Ciência da Informação, Brasília, DF, v. 40, n. 3, p. 349-363, set./dez. 2011. Disponível em: http://revista.ibict.br/ciinf/article/view/1294/1472. Acesso em: 27 jun. 2021.

RODRIGUES, M. R.; CERVANTES, B. M. N. Organização e representação do conhecimento por meio de mapas conceituais. Ciência da Informação, Brasília, DF, v. 41, n. 1, p. 154-169, jan./abr. 2014. Disponível em: http://revista.ibict.br/ciinf/article/view/1425/1603. Acesso em: 27 jun. 2021.

\section{SANTAREM SEGUNDO, J. E. Gestão da informação e do conhecimento e} repositórios digitais: construindo um contexto para o surgimento das competências organizacionais. 2015. 141 f. Dissertação (Mestrado em Ciência da Informação) - Escola de Comunicação e Artes da Universidade de São Paulo, Universidade de São Paulo, São Paulo, 2015. Disponível em: https://repositorio.unesp.br/handle/11449/103346. Acesso em: 27 jun. 2021.

SAYÃO, L. F.; MARCONDES, C. H. Softwares livres para repositórios institucionais: alguns subsídios para a seleção. In: SAYÃO, L. F.; TOUTAIN, L. B.; ROSA, F. G.; MARCONDES, C. H. (org.). Implantação e gestão de repositórios institucionais: políticas, memória, livre acesso e preservação. 
Salvador: EDUFBA, 2009. p. 23-54. Disponível em: https://repositorio.ufba.br/ri/bitstream/ufba/473/3/implantacao_repositorio_web.p df. Acesso em: 27 jun. 2021.

SCHÄFER, M. B.; CONSTANTE, S. E. Políticas e estratégias para a preservação da informação digital. Ponto de Acesso, Salvador, v. 6, n. 3, p. 108-140, dez. 2012. Disponível em: https://portalseer.ufba.br/index.php/revistaici/article/view/6449/4817. Acesso em: 27 jun. 2021.

SILVA, R. A.; RODRIGUES, R. S. Características de repositório educacional aberto para usuários de língua brasileira de sinais. TransInformação, Campinas, v. 25, n. 1, p. 65-79, jan./abr. 2013. Disponível em: http://www.scielo.br/pdf/tinf/v25n1/a07v25n1.pdf. Acesso em: 27 jun. 2021.

\title{
SOUZA, J. A. Gerenciamento de informações sobre o setor cultural:
} proposição de um repositório digital. 2015. 124 f. Dissertação (Mestrado em Estudos de Cultura Contemporânea) - Instituto de Linguagens, Universidade Federal de Mato Grosso, Cuiabá, 2015. Acesso em: http://ri.ufmt.br/handle/1/69. Acesso em: 27 jun. 2021.

SWAN, A. The business of digital repositories. In: WEENIK, K.; WAAIJERS, L.; VAN GODTSENHOVEN, K. (ed.). A DRIVER's guide to european repositories. Amsterdam: Amsterdam University Press, 2007. p. 15-47. Disponível em: https://eprints.soton.ac.uk/264455/. Acesso em: 27 jun. 2021.

WEENINK, K.; WAAIJERS, L.; VAN GODTSENHOVEN, K. (ed.). A DRIVER's guide to european repositories. Amsterdam: Amsterdam University Press, 2007. Disponível em: http://arno.uva.nl/document/93898. Acesso em: 27 jun. 2021.

\section{DIGITAL RPOSITORY: DELIMITING A CONCEPT THROUGH A CONCEPT MAP}

\begin{abstract}
Objective: Conceptualizes digital repository from a set of characteristics presented as essential by the literature. It proposes a conceptual model based on the identified predicates. It adopts concept maps as a way to organize and represent knowledge about digital repository, seen as an object of study in the research. Methodology: It carries out a bibliographical survey that followed four steps, that is, identification of characteristics, definition of categories to group the identified attributes, design of the prototype (on paper), structuring of the prototyped in specific free software, and presentation of the concept map. It is inspired by Joseph Novak's studies (Meaningful Learning Theory), originating a concept map of the spider model, designed and presented in a descriptive and qualitative way. Results: It results in a conceptual map built in CmapTools software, structured by essential characteristics of digital repositories, namely: interactivity and collaboration; interoperability; accessibility; management; self-archiving; software package; and preservation. Conclusions: It is concluded that digital repository
\end{abstract}


constitutes a unified and concise system, based on open, interoperable standards and aligned with the implementation incentive from free and open source software, which provide for management, self-archiving and representation, as well as future access to its digital objects and the institutional memory to which it is subordinate.

Descriptors: Knowledge Organization and Representation. Digital repositories. Conceitual map. CmapTools.

\title{
RESPOSITORIO DIGITAL: DELIMITANDO UM CONCEPTO A TRAVÉS DE UN MAPA CONCEPTUAL
}

\begin{abstract}
RESUMEN
Objetivo: Conceptualiza el repositorio digital a partir de un conjunto de características presentadas como esenciales por la literatura. Propone un modelo conceptual basado en los predicados identificados. Adopta mapas conceptuales como una forma de organizar y representar el conocimiento sobre el repositorio digital, visto como objeto de estudio en la investigación. Metodología: Se realiza un estudio bibliográfico que siguió cuatro pasos, a saber, identificación de características, definición de categorías para agrupar los atributos identificados, diseño del prototipo (en papel), estructuración del prototipo en software libre específico y presentación del mapa conceptual. Se inspira en los estudios de Joseph Novak (Meaningful Learning Theory), originando un mapa conceptual del modelo de araña, diseñado y presentado de forma descriptiva y cualitativa. Resultados: Presenta como resultado un mapa conceptual construido en el software CmapTools, estructurado por intermedio de características esenciales de los repositorios digitales, a saber: interactividad y colaboración; interoperabilidad; accesibilidad; administración; autoarchivo; paquete de software; y preservación. Conclusiones: Se concluye que el repositorio digital constituye un sistema unificado y conciso, basado en estándares abiertos, interoperables y alineado con la implementación de incentivo desde software libre y de código abierto, que contempla la gestión, autoarchivo y representación, así como acceso futuro a sus objetos digitales y a la memoria institucional a la que está subordinado.
\end{abstract}

Descriptores: Organización y representación del conocimiento. Repositorios digitales. Mapa conceptual. CmapTools.

Recebido em: 02.11.2021

Aceito em: 27.12.2021 